\title{
Competition of NO synthases and arginase in the airways hyperreactivity
}

\author{
Anna Strapkova and Martina Antosova \\ Department of Pharmacology, Jessenius Faculty of Medicine, Comenius University, Martin, Slovakia
}

\begin{abstract}
The competition between arginases and NO synthases (NOS) for their common substrate $\mathrm{L}$-arginine can be important in the airways hyperreactivity. We investigated the effect of the simultaneous modulation of arginase and NOS activities in allergen-induced airways hyperreactivity. We analysed the response of tracheal and lung tissue smooth muscle to histamine or acetylcholine after administration $\mathrm{N}^{\omega}$-nitro-L-arginine methyl ester (L-NAME), aminoguanidine (AG) and $\mathrm{N}^{\omega}$-hydroxy-L-arginine (NOHA) in the combinations in in vitro conditions. The results show the decrease of ovalbumin-induced hyperreactivity after inhibition of arginase activity with NOHA. A supplementation of L-arginine caused favourable effect on the airway smooth muscle response. We found the airway reactivity decrease on the whole if we used the combination of NOS and arginase inhibitors. The inhibition of both types of enzymes caused more expressive effect in tracheal smooth muscles. We recorded the difference in the response to histamine or acetylcholine. The simultaneous inhibition of iNOS (with AG) and arginase (with NOHA) evoked the most expressive effect. Results show the importance of competition of both types enzymes - NOS and arginase for the balance of theirs activities in the control of airways bronchomotoric tone in the conditions of the airways hyperreactivity.
\end{abstract}

Key words: Airway hyperreactivity - Ovalbumin - Guinea pig - Arginase - NOS

Abbreviations: AG, aminoguanidine; cGMP, cyclic GMP; eNOS, endothelial NOS; NOS, NO synthase; L-NAME, $\mathrm{N}^{\omega}$-nitro-L-arginine methyl ester; nNOS, neuronal NOS; NOHA, $\mathrm{N}^{\omega}$-hydroxy-Larginine.

\section{Introduction}

Some of the airway diseases (asthma, chronic obstructive pulmonary disease) are characterized by the airway inflammation and airway hyperresponsiveness. The prevalence of these diseases is increasing on regardless of new therapeutic approaches (Stirling and Chung 2000). New insights into the pathophysiology of airway diseases could lead to additional effective therapeutic approaches for their treatment (Ten Broeke et al. 2004). Nitric oxide (NO) might be one of "new" targets, as an extraordinary important bio messenger

Correspondence to: Anna Strapkova, Department of Pharmacology, Jessenius Faculty of Medicine, Comenius University, Sklabinská 26, 03753 Martin, Slovakia

E-mail: astrapkova@jfmed.uniba.sk for a number of inter- and intracellular signalling pathways, including function of respiratory system (Redington 2006). Here, NO causes bronchodilation, vasodilation, it participates in the regulation of gas exchange, blood flow, mucociliary transport, surfactant production and also represents an important non-specific defence mechanism in the airways.

Nitric oxide is produced by family of enzymes NO synthase (NOS) isoforms that utilize the semi-essential amino acid L-arginine as a substrate for the NO and L-citrulline production (Moncada et al. 1989). In the airways the constitutive NOS (cNOS) isoforms are mainly expressed in the neurons of inhibitory nonadrenergic noncholinergic (iNANC) nervous system (nNOS), in the endothelium (eNOS) and in the epithelium (nNOS and eNOS), whereas inducible NOS (iNOS) induced by proinflammatory cytokines during airway inflammation is expressed mainly in macrophages and epithelial cells (Ricciardolo 2003). 
The availability of L-arginine-NO synthesis precursor in the airways is also under control of arginase that hydrolyzes $\mathrm{L}$-arginine to L-ornithine and urea. Arginase 1 is classically considered to be an enzyme of the urea cycle in the liver, but also occurs in extrahepatic tissues including the lung $(\mathrm{Wu}$ and Morris 1998). It is a cytosolic isoform that is expressed mainly in the liver and constitutes more than $98 \%$ of the total body arginase activity. Arginase 2 is a mitochondrial isoform that contributes to the remaining $2 \%$ of the total body arginase activity. It is present in many non-hepatic tissues such as the lung, kidney, prostate, brain, intestine and mammary gland. Both arginase isoforms are constitutively expressed in the airways particularly in the bronchial epithelium and in fibroblasts of peribronchial connective tissue (Que et al. 1998), although Carraway et al. (1998) consider location of isoforms 2 activity predominantly to the lung. Endogenous arginase activity is functionally involved in both the neural and non-neural regulation of the airway smooth muscle tone (Meurs et al. 2000; Antošová et al. 2005) and can impair a neuronal NO-mediated airway smooth muscle relaxation in defined conditions (Maarsingh et al. 2005, 2006).

Since NOS enzymes are expressed in the lung too, this can result in the cross-interaction between both types of enzymes. Both groups - NOS and arginase - use the same substrate therefore simultaneous expression of both enzymes should result in the competition for substrate and thus limit the availability of L-arginine for NO synthesis in optimal quantities. At the same time a maximum activity of arginase is more than 1000-fold higher that of NOS, although the affinity of L-arginine is much higher for NOS than for arginase (Wu and Morris 1998).

There are several lines of evidence suggesting that the NOS/arginase balance in the smooth muscle cell may be involved in the regulation of both bronchial reactivity and airway remodelling. This enzymatic balance regulates both smooth muscle cells proliferation and extracellular matrix deposition, and NO is involved in smooth cell relaxation via cGMP activity. These facts lead to the increasing interest in arginase activity and a potential relevance of competition between arginases and NOS for their common substrate in the airway physiology and pathophysiology, as well (Grasemann et al. 2005; Tadié et al. 2008). Relatively few studies have dealt with the association of NOS - arginases competition in the airway hyperreactivity. The present study investigated the effect of the simultaneous modulation of arginase and NOS activities or an involvement of both enzyme types in the conditions of experimental allergen-induced airways hyperreactivity. We proposed that changed arginase activity could modulate the availability of L-arginine for NOS in these conditions as was documented in some paper (Meuers et al. 2003). How the airways smooth muscle response would be changed if activity of both enzymes was influenced simultaneously? To test this hypothesis we have conducted the study employing the inhibition of both NOS and arginase activity. The non-selective inhibitor $\mathrm{N}^{\omega}$-nitro-L-arginine methyl ester (L-NAME) was used to block activity of predominantly cNOS isoforms, and relatively selective inhibitor aminoguanidine (AG) was used to block the activity of iNOS isoform. The $\mathrm{N}^{\omega}$-hydroxy-L-arginine (NOHA) was used to block the activity of arginase. It is known that NOHA is an intermediate in the biosynthesis of NO by NOS and has been found to be a physiological competitive inhibitor of arginase (Daghigh et al. 1994). Agents were applied in the combinations in in vitro conditions using a method of organ baths.

\section{Materials and Methods}

\section{Animals and agents}

Pathogens-free adult male Trik strain guinea pigs weighing 200-250 g were used in our study from approved breeding facility (Department of Toxicology and Breeding of Experimental Animals, Department of Experimental Pharmacology Slovak Academy of Sciences, Dobrá Voda, Slovak Republic). Animals were group-housed in individual cages in climatecontrolled animal quarters and received water and food ad libitum. Room temperature was maintained at $21 \pm 1^{\circ} \mathrm{C}$ upon a $12 / 12 \mathrm{~h} \mathrm{light/dark}$ regimen. The study protocol was approved by the local Ethical Committee of Jessenius Faculty of Medicine. Animal care, procedures of allergen-induced airways hyperreactivity and euthanasia with small guillotine were performed in accordance with internationally accepted recommendations - Helsinki declaration World Medical Association, Direction of European Commission on the protection of animals used for experimental and other scientific purposes (86/609/EHS, 1986) and statute valid in Slovak Republic (Law No. 289/2003 Statute-book Regulation of Slovak Republic).

In our experiments six groups of samples of tracheal and lung tissue smooth muscles from animals with ovalbumininduced airways hyperreactivity were designed as follows (NOHA was administered in equal dose $(10 \mu \mathrm{mol} / 30 \mathrm{ml}$ organ bath) to all Groups 1-5):

Group 1 - NOHA $(n=8)$

Group 2 - NOHA+L-arginine $\left(10^{-4} \mathrm{~mol} / \mathrm{l}\right)(n=8)$

Group 3 - NOHA+L-NAME $\left(10^{-4} \mathrm{~mol} / \mathrm{l}\right)(n=6)$

Group 4 - NOHA+AG $\left(10^{-4} \mathrm{~mol} / \mathrm{l}\right)(n=6)$

Group 5 - NOHA+L-NAME $\left(10^{-4} \mathrm{~mol} / \mathrm{l}\right)+\mathrm{AG}\left(10^{-4} \mathrm{~mol} / \mathrm{l}\right)$ $(n=6)$

Control group - saline $(0.2 \mathrm{ml})(n=8)$.

\section{Model of allergen-induced hyperreactivity}

The modified method of Fraňová et al. (2001), the senzibilization of guinea pigs by allergen (ovalbumin) was used to 
induce the airways hyperreactivity. The allergen solution containing $100 \mu \mathrm{mol}$ ovalbumin in saline was injected in exact time interval - at the 1 st day $0.5 \mathrm{ml}$ administered intraperitoneally and $0.5 \mathrm{ml}$ subcutaneously, at the $3 \mathrm{rd}$ day $1 \mathrm{ml}$ was administered intraperitoneally and at the 14 th day $1 \mathrm{ml}$ of solution was nebulized and inhaled into the respiratory system. The inhalation of ovalbumin was performed in a body plethysmograph (Hugo Sachs Electronic, type 885, Germany) for rodents and small animals.

\section{Airway responsiveness}

Animals were euthanized 24 hours after the inhalation of ovalbumin. Strips were prepared from trachea and lung tissue and placed into organ bath with Krebs-Henseleit solution (in mol/l: $110.0 \mathrm{NaCl}, 4.8 \mathrm{KCl}, 2.35 \mathrm{CaCl}_{2}, 1.20 \mathrm{MgSO}_{4}, 1.20$ $\mathrm{KHPO}_{4}, 25.0 \mathrm{NaHCO}_{3}$ and $4 \mathrm{~g}$ glucose in glass-distilled water). The solution was continuously aerated with mixture of $95 \% \mathrm{O}_{2}$ and $5 \% \mathrm{CO}_{2}$ at $\mathrm{pH} 7.5 \pm 0.1$ and temperature $36 \pm 0.5^{\circ} \mathrm{C}$. One of the strip endings was connected to a force transducer (TSR 10G, Vývoj Martin, Slovak Republic) and an amplifier (M1101 SUPR, Mikrotechna Praha, Czech Republic) and tension records were made on a Line Recorder TZ 4620 (Laboratorní př́stroje Praha, Czech republic). The changes of tension were recorded on a computer with specific software (RES s.r.o, Martin, Slovak Republic). The tissue strips were exposed initially to the tension of $4 \mathrm{~g}$ (30 minutes - loading phase). Then, the tension was readjusted to a baseline of $2 \mathrm{~g}$ (30 minutes - adaptive phase). The KrebsHenseleit solution was changed every 10 minutes. Inhibitors of arginase and NO synthases were added to organ baths 30 minutes before the evaluation of smooth muscles responses to bronchoconstrictive mediators. The strips contraction was induced by cumulative doses $\left(10^{-8}-10^{-3} \mathrm{~mol} / \mathrm{l}\right)$ of histamine or acetylcholine (Sigma Aldrich ${ }^{\circledR}$ ).

\section{Statistical analysis}

All data are expressed as the mean \pm S.E.M. The data for each group and differences between the groups were analyzed using the ANOVA test. $p<0.05$ was considered to be statistically significant.

\section{Results}

The difference in the airway reactivity between guinea pig sensitized with ovalbumin and non-sensitized control animals challenged with histamine were described in our previous papers. The sensibilization with ovalbumin caused the statistically significant increase of the tracheal as well as lung tissue smooth muscle reactivity (Strapková et al. 2008a).

We have found that NOHA - arginase inhibitor, in a dose of $10 \mu \mathrm{mol} /$ organ bath significantly reduced tracheal smooth muscle reactivity to histamine at the concentration $10^{-6} \mathrm{~mol} / \mathrm{l}$ $(p<0.05)$ and $10^{-5}-10^{-3} \mathrm{~mol} / \mathrm{l}(p<0.01)$ when comparing to control group. Interestingly, NOHA $(10 \mu \mathrm{mol})$ added to the organ bath did not evoke a statistically significant response of lung tissue smooth muscle (Fig. 1).

It is evident that $10 \mu \mathrm{mol}$ NOHA also caused statistically significant decrease $(p<0.05)$ of the tracheal smooth muscle contraction amplitude as a response to acetylcholine at the
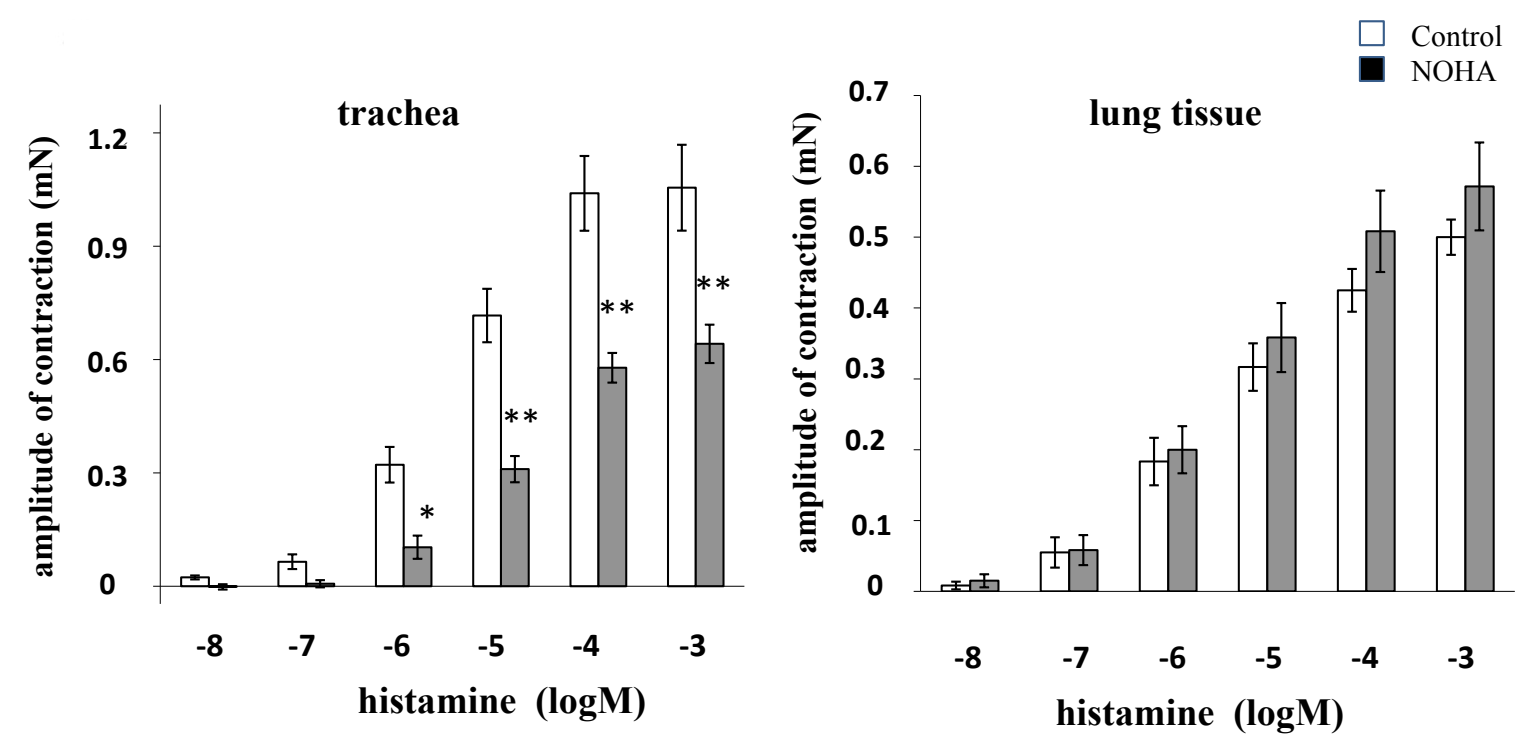

Figure 1. Effect of NOHA (10 $\mu \mathrm{mol} /$ organ bath in vitro) on the reactivity of tracheal (left) and lung (right) tissue smooth muscle to histamine. ${ }^{\star} p<0.05 ;{ }^{* *} p<0.01$. 

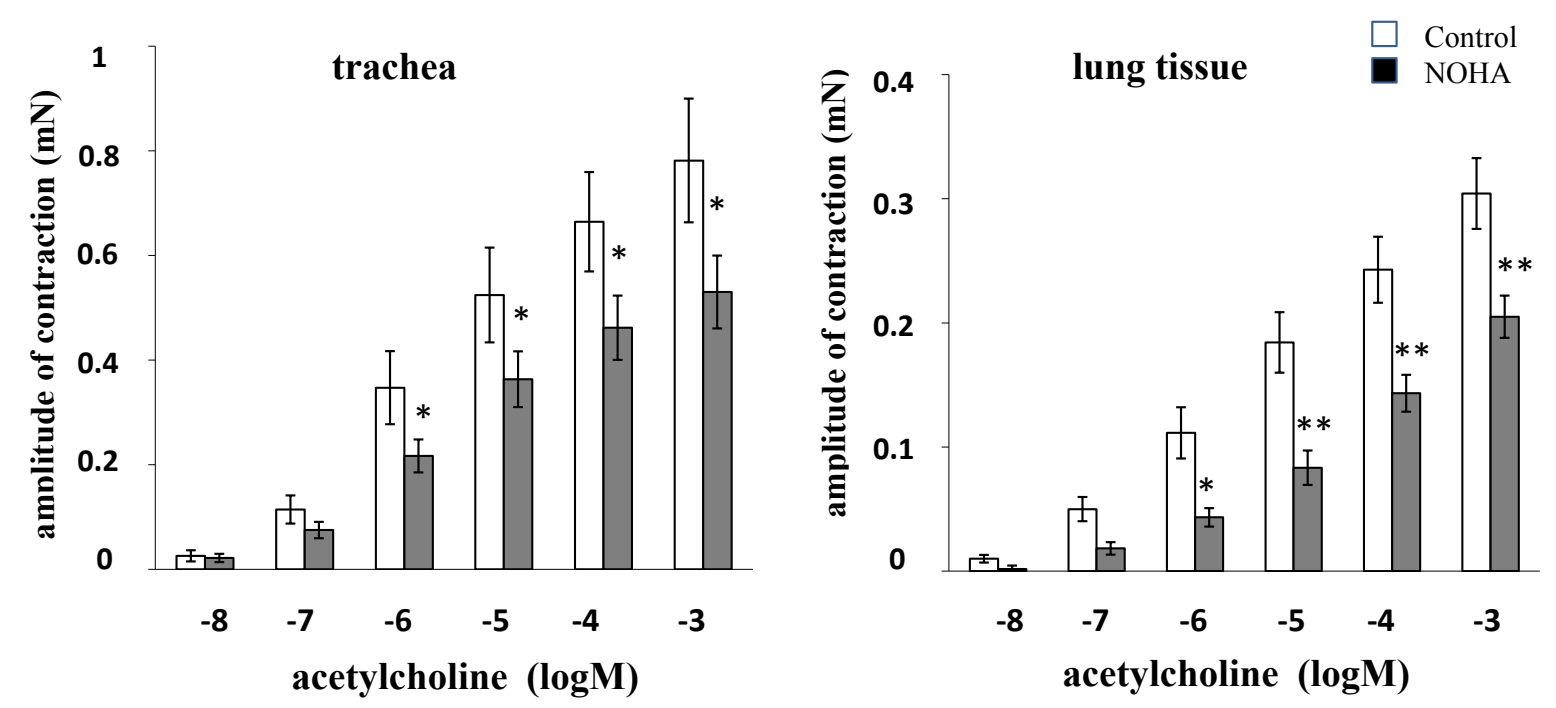

Figure 2. Effect of NOHA (10 $\mu \mathrm{mol}$ /organ bath in vitro) on the reactivity of tracheal (left) and lung (right) tissue smooth muscle to acetylcholine. ${ }^{\star} p<0.05 ;{ }^{\star *} p<0.01$.

concentration $10^{-6}-10^{-3} \mathrm{~mol} / \mathrm{l}$ in comparison with the group of animal without NOHA. Similar response to acetycholine was detected for lung tissue smooth muscle. The fall of the contraction amplitude was statistically significant in acetylcholine concentration $10^{-6} \mathrm{~mol} / \mathrm{l}(p<0.05)$ and $10^{-5}-10^{-3}$ $\mathrm{mol} / \mathrm{l}(p<0.01)$ (Fig. 2).

Combination of L-arginine $\left(10^{-4} \mathrm{~mol} / \mathrm{l}\right)+\mathrm{NOHA}$ in a dose of $10 \mu \mathrm{mol}$ decreased the tracheal smooth muscle contraction amplitude more significantly than NOHA alone $(10 \mu \mathrm{mol})$ at the concentration of histamine $10^{-5}-10^{-3} \mathrm{~mol} / \mathrm{l}$ $(p<0.05)$ (Fig. 3). The response of tracheal smooth muscle to another bronchoconstrictive mediator - acetylcholine was similar but not significant.

All combinations of inhibitors evoked the decrease of the tracheal smooth muscle contraction amplitude to histamine on the whole (Fig. 4), when comparing to baseline reactivity using saline. The most effective was the combination of NOHA+AG that caused statistically significant fall in all histamine concentrations $10^{-8}-10^{-6} \mathrm{~mol} / \mathrm{l}(p<0.05)$, $10^{-5}-10^{-4} \mathrm{~mol} / \mathrm{l}(p<0.01)$ and $10^{-3} \mathrm{~mol} / \mathrm{l}(p<0.001)$. The decrease was similar (mainly at higher histamine concentration: $10^{-6}-10^{-3} \mathrm{~mol} / \mathrm{l}$ ) if the combination $\mathrm{NOHA}+\mathrm{L}-\mathrm{NAME}$

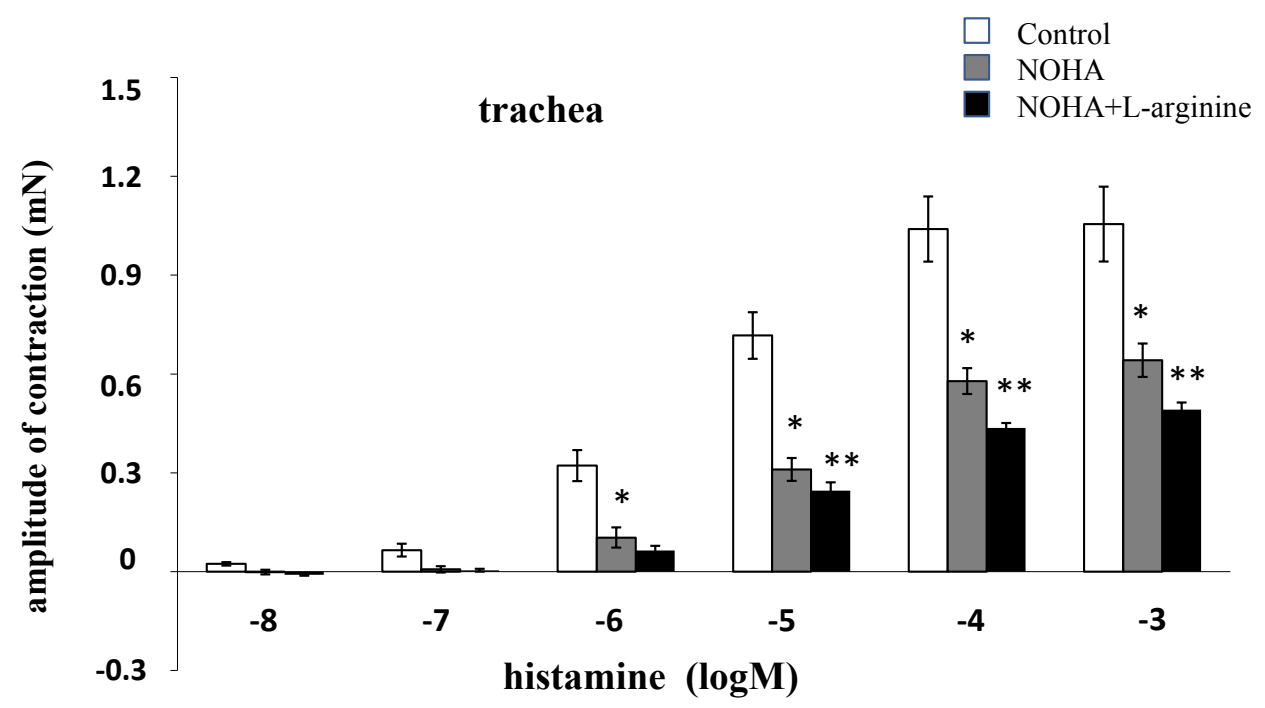

Figure 3. Comparison of effect of NOHA $(10 \mu \mathrm{mol} /$ organ bath in vitro $)$ and combination of NOHA+L-arginine $\left(10^{-4} \mathrm{~mol} / \mathrm{l}\right)$ on the reactivity of tracheal smooth muscle to histamine. ${ }^{*} p<0.05 ;{ }^{* *} p<0.01$. 

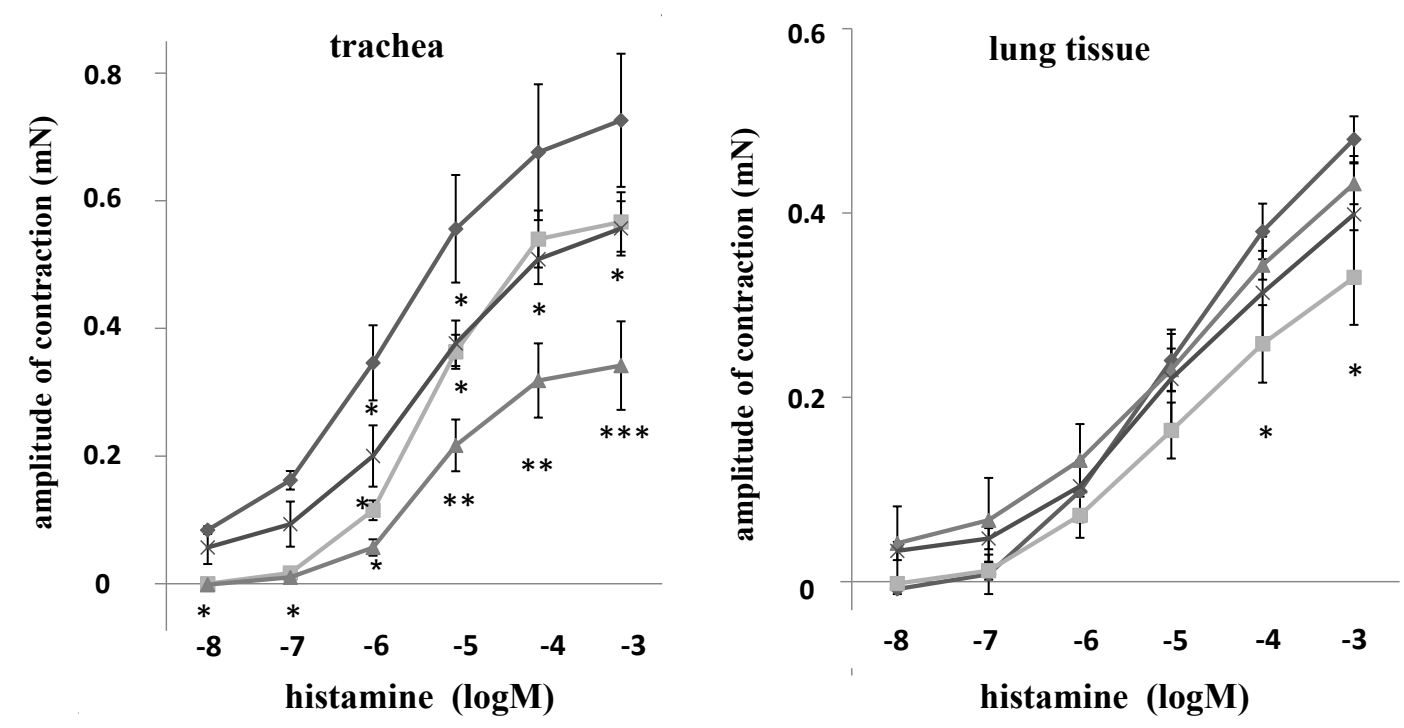

Figure 4. Effect of combination of NOHA ( $10 \mu \mathrm{mol} /$ organ bath in vitro $)+\mathrm{L}-\mathrm{NAME}\left(10^{-4} \mathrm{~mol} / \mathrm{l}\right), \mathrm{NOHA}+\mathrm{AG}\left(10^{-4} \mathrm{~mol} / \mathrm{l}\right)$ and NOHA+LNAME+AG on the reactivity of tracheal (left) and lung (right) smooth muscle to histamine. ${ }^{\star} p<0.05$; $^{* *} p<0.01$; $^{* * *} p<0.001$. ${ }^{\star}$ control; - NOHA+L-NAME; $\Delta \mathrm{NOHA+AG;} \mathrm{NOHA}+\mathrm{L}-\mathrm{NAME}+\mathrm{AG}$.

and $\mathrm{NOHA}+\mathrm{L}-\mathrm{NAME}+\mathrm{AG}$ were used. The decrease of the contraction amplitude was statistically significant using histamine concentration $10^{-6}-10^{-3} \mathrm{~mol} / \mathrm{l}(p<0.05)$ if combination $\mathrm{NOHA}+\mathrm{L}-\mathrm{NAME}+\mathrm{AG}$ was used. The combination $\mathrm{NOHA}+\mathrm{L}-\mathrm{NAME}$ caused the decrease of trachea response in the histamine concentration $10^{-6}-10^{-5} \mathrm{~mol} / \mathrm{l}(p<0.05)$.

The response of lung tissue smooth muscle (Fig. 4) in the same conditions was less expressive in general than in the tracheal smooth muscle. We recorded statistically significant decrease only in the combination of $\mathrm{NOHA}+\mathrm{L}-$ NAME to adding of histamine $\left(10^{-4}-10^{-3} \mathrm{~mol} / \mathrm{l}\right)(p<0.05)$. The response of lung tissue smooth muscle to combination $\mathrm{NOHA}+\mathrm{AG}$ and $\mathrm{NOHA}+\mathrm{L}-\mathrm{NAME}+\mathrm{AG}$ was statistically non-significant.

The response of tracheal smooth muscle to acetylcholine was significantly increased in the concentration $10^{-6}-10^{-5}$
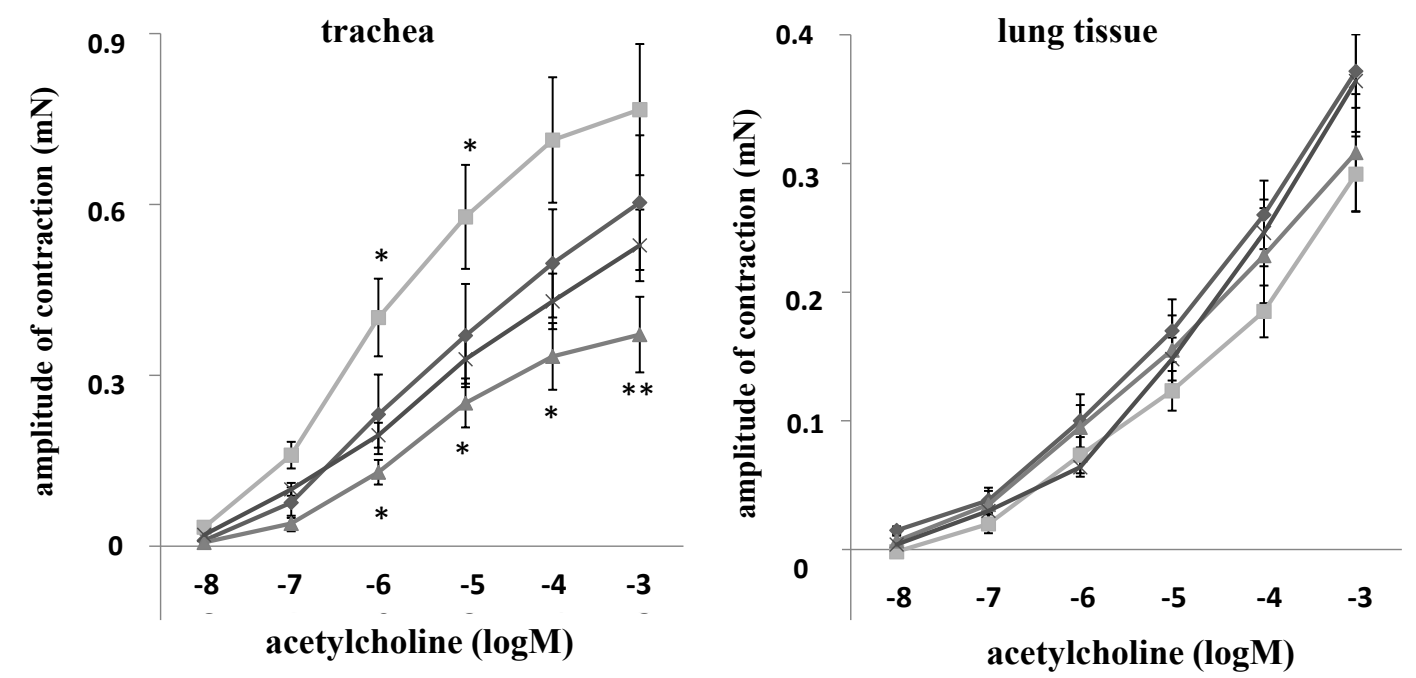

Figure 5. Effect of combination of NOHA $(10 \mu \mathrm{mol} /$ organ bath in vitro $)+\mathrm{L}-\mathrm{NAME}\left(10^{-4} \mathrm{~mol} / \mathrm{l}\right), \mathrm{NOHA}+\mathrm{AG}\left(10^{-4} \mathrm{~mol} / \mathrm{l}\right)$ and NOHA+LNAME+AG on the reactivity of tracheal (left) and lung (right) smooth muscle to acetylcholine. ${ }^{\star} p<0.05 ;{ }^{* *} p<0.01 ;{ }^{\star * \star} p<0.001$. - control; NOHA+L-NAME; $\boldsymbol{\Delta} \mathrm{NOHA}+\mathrm{AG}$; $\mathrm{N}$ NOHA+L-NAME+AG. 
$\mathrm{mol} / \mathrm{l}(p<0.05)$ if the combination of $\mathrm{NOHA}+\mathrm{L}-\mathrm{NAME}$ was added to organ bath. The combination of $\mathrm{NOHA}+\mathrm{AG}$ caused the most expressive decrease of the response of tracheal smooth muscle in concentration $10^{-6}-10^{-4} \mathrm{~mol} / \mathrm{l}(p<0.05)$ and $10^{-3} \mathrm{~mol} / \mathrm{l}(p<0.01)$ of acetylcholine. Similar tendency of the response, but statistically non-significant to the control group, was showed if we added the combination $\mathrm{NOHA}+\mathrm{L}-$ NAME+AG into organ bath. The responses of lung tissue smooth muscles to acetylcholine had similar shape in all groups but were statistically non-significant (Fig. 5).

\section{Discussion}

NOS and arginase compete for the common substrate, Larginine. In addition to the NO synthases some of the cells of respiratory system involving the bronchial smooth muscle cells express one or both of arginase isoenzymes (1 and 2) that represent a major alternate route of arginine metabolism (Wu and Morris 1998). The activity and role of arginase in the airway (in the health or in the diseases) is interesting and not completely clear and is thus constantly discussed. A growing number of studies have found induction of arginase activity and its expression in a variety of inflammatory conditions suggesting that the arginase may play important role in the pathophysiology of inflammatory respiratory diseases (Tadié et al. 2008).

It is proposed that mainly three enzymes are up-regulated in model of allergic airway disease and in patients with asthma - arginase 1 , arginase 2 and iNOS that result to a change in NO homeostasis. Several reports have demonstrated the significant increase in both isoforms arginase activity. Takemoto et al. (2007) found a significant transient increase in both arginases activity after sensitization in mice not only in the lung but also in serum. Expression of arginase 1 was modestly increased in bronchiolar epithelium and was highly expressed in inflammatory cells in response to sensitization. They found simultaneous upregulation of iNOS mRNA expression in the lung tissue. Thus, the course of iNOS mRNA expression paralleled that of arginase. No change was found in the eNOS and nNOS.

Therefore, we followed in our experiments the changes in ovalbumin-induced hyperreactivity after inhibition of both - NOS and arginase. In previous experiment we inhibited arginase by NOHA in two doses 5 or $10 \mu \mathrm{mol}$ administered into organ baths to airway specimens (Strapková and Antošová 2009). The inhibition of arginase activity by NOHA produced the dose-dependent effect if higher dose of arginase inhibitor NOHA provoked more expressive effect. We propose that a potency of lower dose was probably weak for full inhibition of arginase activity and for inhibition of its detrimental effects. In addition, reduced L-arginine availability for NOS by arginase may lead to an increased production of peroxynitrite, contributing to cell damage and increased airway smooth muscle contractility (Maarsingh et al. 2009). Similar results were obtained by Ckless et al. (2008) who reported that the inhibition of arginase led to an augmentation of the inflammatory response and bronchial hyperreactivity in mouse model. Therefore we used higher dose of NOHA $(10 \mu \mathrm{mol})$ for inhibition arginase in our experiment.

The interest in arginase activities is growing because limitation of L-arginine bioavailability by arginase for NO synthesis from constitutive NOS can contribute to asthma and airway hyperreactivity. It is interesting that pathway of arginine metabolism may differ in different types of allergen-induced bronchial hyperreactivity and the importance of NO may differ in different asthma triggers. That can be due to contrasting levels of arginase activity (Greene et al. 2005). Arginase has been implicated in the pathogenesis of asthma in several ways. First is reduction of L-arginine availability that can limit NO production. This assumption we documented in part of experiments where we used supplementation of L-arginine in the concentration $10^{-4} \mathrm{~mol} / \mathrm{l}$ together with NOHA in a dose of $10 \mu \mathrm{mol}$. We recorded the relaxant response of the airways smooth muscle to arginase inhibition and a potentiation of this response by supplementation of L-arginine that confirms thesis of a decrease in NO bioavailability in the airway dysfunction. The inhibition of arginase can restore $\mathrm{NO}$ signalling role and airway tone by regulating of L-arginine availability for NOS activity, cGMP production and smooth muscle relaxation (Berkowitz et al. 2003).

Other hypothesis of the arginase participation in the airways smooth muscle control proposes that the increased L-arginine content in the airway can control arginase expression directly or indireactly through iNOS, specifically through NOHA production. So, effect of arginase inhibition on the development of airway hyperreactivity may be iNOSdependent (Bratt et al. 2010). The inhibition of arginase activity that occurs by NOHA during marked iNOS induction may be a mechanism to ensure sufficient arginine availability for high-output production of NO (Buga et al. 1996). Arginase also redirects the metabolism of L-arginine to L-ornithine and the formation of polyamines and L-proline that are essential for airway remodelling that play important role in bronchial hyperreactivity, too (Durante et al. 2007). Competition or balance between NOS and arginase activities is important factor. This question we tried to clarify by using of combination of NOS and arginase inhibitors. We found the airway reactivity decrease on the whole. The effect of inhibition of both types of enzymes was more expressive at level of tracheal smooth muscles. The results show fall of the contraction amplitude of tracheal smooth muscles in histamine mainly. The effect was the most expressive at the inhibition of iNOS (AG) and arginase (NOHA). The inhi- 
bition of cNOS (L-NAME) and arginase (NOHA) caused only weak reactivity changes (weak decrease of tracheal smooth muscle response to histamine). The response of tracheal smooth muscle to acetylcholine was different. The combination NOHA+L-NAME caused the increase in the trachea response, $\mathrm{NOHA}+\mathrm{AG}$ caused the expressive decrease and combination NOHA+L-NAME+AG was without effect. So, in our study, inhibition of both "detrimental" enzymes (iNOS and arginase) caused a beneficial effect. We can see different results in same papers that can be caused by species differences, too (Kitowska et al. 2008). Singh et al. (2007) shows that selective iNOS inhibition effectively reduces exhaled NO but does not affect airway hyperreactivity or airway inflammatory cell numbers after allergen challenge in subjects with asthma.

The lung tissue smooth muscle responded very weakly (only to combination of NOHA with L-NAME that provoked a decrease of contraction amplitude). We assume that the difference in the affection of used agents at different levels of airway can arise from the different localization of enzymes utilizing L-arginine as well as the antioxidant mechanisms in the upper and lower airway (Strapková et al. 2008b). Another fact can be important that NOS neurons utilizing L-arginine are higher in number in proximal than distal airways and NO acts as bronchodilator mainly in proximal airways (Prado et al. 2005). It is probably a reason why NO prevents more the contraction of the large airways than small ones (Dewachter et al. 1997). Also, North et al. (2009) obtained different response of the central and peripheral airways. They determined expression of arginase 1 , arginase 2 and NOS isoenzymes in asthma patients and in murine model of ovalbumin-induced airway inflammation. Expression of arginase 1 was increased in human asthma, whereas arginase 2 and NOS isoforms were unchanged. In the acute allergic airway inflammation arginase 1 , arginase 2 , nNOS and iNOS were increased, whereas eNOS expression was decreased. Arginase inhibition in vivo attenuated the methacholine responsiveness of the central airways in acute model. In the chronic model only arginase 1 expression was increased. Interestingly, in the chronic model, which generates an airway remodeling, arginase inhibition attenuated methacholine responsiveness of the central and peripheral airways. Another possible clarification for different effect of lung tissue is possibility that lung can respond to ovalbumin challenge with an adaptive response of the large airways that includes regulation of the concentration of arginine within cells of the airway epithelium and subepithelial layer (Kenyon et al. 2008).

We recorded the difference in the response of the airways to used mediators of bronchoconstriction - histamine or acetylcholine. This difference is likely due to differences in the contribution of a neural reflex mechanism. Histamine causes bronchoconstriction not only directly by inducing the contraction of airway smooth muscle through its receptors but also indirectly via the excitation of a cholinergic pathway by neural reflex. Acetylcholine, in contrast, is less effective in eliciting bronchoconstriction by neural reflex. We can suppose that differences in the localization of different receptors for these mediators or an alternative nervous system of airway (iNANC nervous system with vasoactive intestinal polypeptide, sympathetic nervous system etc.) could be due to these responses (Matsumoto et al. 1997). Ckless et al. (2008) speculate that changes in respiratory mechanics in their study are due to altered permeability of the airways in association with enhanced inflammation, which could perhaps allow increased access of methacholine to smooth muscle cells.

Our experiments show the effect of the modulation of NOS and arginase activity in the conditions of ovalbumininduced airway hyperreactivity. Results point out to the importance of optimal balance in the activity of NOS and arginase. They confirm that competition of NOS and arginase in common substrate L-arginine may be one of important factors influencing the condition of the bronchomotoric tone in the airway hyperreactivity. Both types of enzymes, but arginase mainly, offer another possibility for therapeutic intervention in respiratory diseases attending with bronchial hyperreactivity. Further studies will be required to determine how the balance of metabolism of arginine is regulated in airway cells, and which of these metabolic pathways (arginase, NOS pathways) are critical in arginine metabolism in airway hyperreactivity.

Acknowledgement. This work was supported by project "Center of Experimental and Clinical respirology" co-financed from EC sources and VEGA grant 1/0010/10.

\section{References}

Antošová M., Strapková A., Nosálová G. (2005): The activity of arginase and nitric oxide synthase in bronchial hyperreactivity. Abstr. Nitric Oxide, basic regulations and pharmacological interventions, Tučepi, Croatia p. 44

Berkowitz D. E., White R., Li D., Minhas K. M., Cernetich A., Kim S., Burke S., Skoukas A. A., Nyhan D., Champion H. C., Hare J. M. (2003): Arginase reciprocally regulates nitric oxide synthase activity and contributes to endothelial dysfunction in aging blood vessels. Circulation 108, 2000-2006 doi:10.1161/01.CIR.0000092948.04444.C7

Bratt J. M., Franzi L. M., Linderholm A. L., O'Roark E. M., Kenyon N. J., Last J. A. (2010): Arginase inhibition in airways from normal and nitric oxide synthase 2-knockout mice exposed to ovalbumin Toxicol. Appl. Pharmacol. 242, 1-8 doi:10.1016/j.taap.2009.09.018

Buga G. M., Singh R., Pervin S., Rogers N. E., Schmitz D. A., Jenkinson C. P., Cederbaum S. D., Ignarro L. J. (1996): Arginase activity in endothelial cells: inhibition by NG-hydroxy-L-arginine 
during high-output NO production. Am. J. Physiol. Heart Circ. Physiol. 271, H1988-1998

Carraway M. S., Piantadosi C. A., Jenkinson C. P., Huang Y. C. (1998): Differential expression of arginase and iNOS in the lung in sepsis. Exp. Lung. Res. 24, 253-268 doi:10.3109/01902149809041533

Ckless K., Lampert A., Reiss J., Kasahara D., Poynter M. E., Irvin C. G., Lundblad L. K., Norton R., van der Vliet A., Janssen-Heininger Y. M. (2008): Inhibition of arginase activity enhances inflammation in mice with allergic airway disease, in association with increases in protein S-nitrosylation and tyrosine nitration. J. Immunol. 181, 4255-4264

Daghigh F., Fukuto J. M., Ash D. E. (1994): Inhibition of rat liver arginase by an intermediate in NO biosynthesis, NG-hydroxy-L-arginine: implications for the regulation of nitric oxide biosynthesis by arginase. Biochem. Biophys. Res. Commun. 202, 174-180 doi:10.1006/bbrc.1994.1909

Dewachter P., Vassiliou M., Saunier C. G., Hartemann D., Peslin R. Laxenaire M. C. (1997): Effect of the inhibitor of NO synthase, NG-nitro-L-arginine methyl ester, on histamine-induced bronchospasm in the rabbit. Acta Physiol. Scand. 161, 47-53 doi:10.1046/j.1365-201X.1997.00180.x

Durante W., Johnson F., Johnson R. A. (2007): Arginase: a critical regulator of nitric oxide synthesis and vascular function. Clin. Exp. Pharmacol. Physiol. 34, 906-911

doi:10.1111/j.1440-1681.200

Fraňová S. (2001): The influence of inhaled furosemide on adverse effects of ACE-inhibitors in airways. Bratisl. Lek. Listy 102, 309-313

Grasemann H., Schwiertz R., Matthiesen S., Racké K., Ratjen F. (2005): Increased arginase activity in cystic fibrosis airways. Am. J. Respir. Crit. Care Med. 172, 1523-1528 doi:10.1164/rccm.200502-253OC

Greene A. L., Rutherford M. S., Regal R. R., Flickinger G. H., Hendrickson J. A., Giulivi C., Mohrman M. E., Fraser D. G., Regal J. F. (2005): Arginase activity differs with allergen in the effector phase of ovalbumin- versus trimellitic anhydride-induced asthma. Toxicol. Sci. 88, 420-433 doi:10.1093/toxsci/kfi311

Kenyon N. J., Bratt J. M., Linderholm A. L., Last M. S., Last J. A. (2008): Arginases I and II in lungs of ovalbumin-sensitized mice exposed to ovalbumin: Sources and consequences. Toxicol. Appl. Pharmacol. 230, 269-275

doi:10.1016/j.taap.2008.03.004

Kitowska K., Zakrzewicz D., Königshoff M., Chrobak I., Grimminger F., Seeger W., Bulau P., Eickelberg O. (2008): Functional role and species-specific contribution of arginases in pulmonary fibrosis. Am. J. Physiol. Lung Cell. Mol. Physiol. 294, L34-45 doi:10.1152/ajplung.00007.2007

Maarsingh H., Tio M. A., Zaagsma J., Meuers H. (2005): Arginase attenuates inhibitory nonadrenergic noncholinergic nerveinduced nitric oxide generation and airway smooth muscle relaxation. Resp. Res. 6, 23-28 doi:10.1186/1465-9921-6-23

Maarsingh H., Leusink J., Bos I. S., Zaagsma J., Meuers H. (2006): Arginase strongly impairs neuronal nitric oxide-mediated airway smooth muscle relaxation in allergic asthma. Resp. Res. 7, 6-12 doi:10.1186/1465-9921-7-6
Maarsingh H., Bossenga B. E., Bos I. S., Volders H. H., Zaagsma J., Meurs H. (2009): L-arginine deficiency causes airway hyperresponsiveness after the late asthmatic reaction. Eur. Respir. J. 34, 191-199 doi:10.1183/09031936.00105408

Matsumoto K., Aizawa H., Takata S., Inoue H., Takahashi N., Hara N. (1997): Nitric oxide derived from sympathetic nerves regulates airway responsiveness to histamine in guinea pigs. J. Appl. Physiol. 83, 1432-1437

Meurs H., Hamer M. A., Pethe S., Vadon-Le G. S., Boucher J. L., Zaagsma J. (2000): Modulation of cholinergic airway reactivity and nitric oxide production by endogenous arginase activity. Br. J. Pharmacol. 130, 1793-1798 doi:10.1038/sj.bjp.0703488

Meuers H., Maarsingh H., Zaagsma J. (2003): Arginase and asthma: novel insights in nitric oxide homeostasis and airway hyperresponsiveness. TIPS 24, 450-455 doi:10.1016/S0165-6147(03)00227-X

Moncada S., Palmer R. M., Higgs E. A. (1989): Biosynthesis of nitric oxide from $\mathrm{L}$-arginine. A pathway for the regulation of cell function and communication. Biochem. Pharmacol. 38, 1709-1715 doi:10.1016/0006-2952(89)90403-6

North M. L., Khanna N., Marsden P. A., Grasemann H., Scott J. A. (2009): Functionally important role for arginase 1 in the airways hyperresponsiveness of asthma. Am. J. Physiol. Lung Cell. Mol. Physiol. 296, L911-920 doi:10.1152/ajplung.00025.2009

Prado C. M., Leick-Maldonado E. A., Kasahara D. I., Capelozzi V. L., Martins M. A., Tibério I. F. (2005): Effects of acute and chronic nitric oxide inhibition in an experimental model of chronic pulmonary allergic inflammation in guinea pigs. Amer. J. Physiol. Lung Cell. Mol. Physiol. 289, L677-683 doi:10.1152/ajplung.00010.2005

Que L.G., Kantrow S. P., Jenkinson C. P., Piantadosi C. A., Huang Y. C. (1998): Induction of arginase isoforms in the lung during hyperoxia. Am. J. Physiol. 275, L96-102

Redington A. E. (2006): Modulation of nitric oxide pathway: Therapeutic potential in asthma and chronic obstructive pulmonary disease. Eur. J. Pharmacol. 533, 263-276 doi:10.1016/j.ejphar.2005.12.069

Ricciardolo F. L. M. (2003): Multiple role of nitric oxide in the airways. Thorax 58, 175-182 doi:10.1136/thorax.58.2.175

Ricciardolo F. L. M., Sterk P. J., Gaston B., Folkerts G. (2004): Nitric oxide in health and disease of the respiratory system. Physiol. Res. 84, 731-765 doi:10.1152/physrev.00034.2003

Singh D., Richards D., Knowles R. G., Schwartz S., Woodcock A., Langley S., O'Connor B. J. (2007): Selective inducible nitric oxide synthase inhibition has no effect on allergen challenge in asthma. Am. J. Respir. Crit. Care Med. 176, 988-993 doi:10.1164/rccm.200704-5880C

Stirling R. G., Chung K. F. (2000): Future treatments of allergic diseases and asthma. Br. Med. Bull. 56, 1037-1053 doi:10.1258/0007142001903526

Strapková A., Antošová M., Nosálová G. (2008a): Effect of NOsynthase and arginase inhibition in airway hyperreactivity. Bratisl. Lek. Listy 109, 191-197 
Strapková A., Antošová M., Nosálová G. (2008b): Relation of Larginine to the airway hyperreactivity. Gen. Physiol. Biophys. 27, 85-91

Strapková A., Antošová M. (2009): Arginase in the airways hyperreactivity. Bratisl. Lek. Listy 110, 592-597

Tadié J-M., Henno P., Leroy I., Danel C., Naline E., Faisy Ch., Riquet M., Levy M., Isräel-Biet D., Delclaux Ch. (2008): Role of nitric oxide synthase/arginase balance in bronchial reactivity in patients with chronic obstructive pulmonary disease. Am. J. Physiol. Lung Cell. Mol. Physiol. 294, L489-497 doi:10.1152/ajplung.00109.2007

Takemoto K., Ogino K., Shibamori M., Gondo T., Hitomi Y., Takigawa T., Wang D., Takaki J., Ichimura H., Fujikura Y., Ishiyama H. (2007): Transiently, paralleled upregulation of arginase and nitric oxide synthase and the effect of both enzymes on the pathology of asthma. Am. J. Physiol. Lung Cell. Mol. Physiol. 293, L1419-1426 doi:10.1152/ajplung.00418.2006

Ten Broeke R., Blalock J. E., Nijkamp F. P., Folkerts G. (2004): Calcium sensors as new therapeutic targets for asthma and chronic obstructive pulmonary disease. Clin. Exp. Allergy 34, $170-176$

doi:10.1111/j.1365-2222.2004.01908.x

Wu G., Morris S. M. Jr. (1998): Arginine metabolism: nitric oxide beyond. Biochem. J. 336, 1-17

Received: April 7, 2010

Final version accepted: September 7, 2010 